\title{
A Spatial Analysis of Human Development and the Level of Women Empowerment in the Karnataka State
}

\author{
Pradeep Kumar $\mathrm{K}^{*}$, Sowmyashree $\mathrm{K} \mathrm{L}^{\dagger}$ and \\ B Chandrashekara ${ }^{\ddagger}$
}

\begin{abstract}
The present investigation aims at analyzing the regional disparities in the levels of Human development and finding out the relationship between the Human development and the level of women empowerment in the Karnataka state. Five variables namely; Female Literacy rate to total literacy rate, Sex ratio, Child sex ratio, working female Population to total working population and Total crime against women have been taken into consideration to assess the levels of women empowerment of the state. District wise secondary data has been collected from census and the Karnataka State human development report. The Composite index method has been computed to ascertain the level of women empowerment, which is depicted in choropleth map, and the correlation co-efficient, is used to find out the relationship between Human development index and the level of women empowerment. The analysis reveals that the southern and coastal parts of Karnataka have a higher share of human development index and higher
\end{abstract}

\footnotetext{
Research Scholar, Department of Studies in Geography, Manasagangothri, Mysore - 570 006; pradeepkabballi@gmail.com

† Research Scholar, Department of Studies in Geography, Manasagangothri, Mysore - 570006

‡ Associate Professor, Department of Studies in Geography, Manasagangothri, Mysore - 570 006; drchandru1966@yahoo.com
} 
level of women empowerment. The study also reveals that there is a positive relationship between human development and the level of women empowerment in the state.

Keywords: Human development index; Women empowerment; Literacy; Working population

\section{Introduction}

In the recent decades, the concept of women empowerment has undergone a sea change from welfare oriented approach of women empowerment to the equity approach. Many researchers of different disciplines have been interested about the concept of women empowerment, because Women empowerment is one of the essential factors that promote human development in a region. The empowerment of women and the improvement of their political, social, economic and health status is important for sustainable human development.

Human Development and the Women empowerment are both positively correlated with each other. In fact, empowered women can contribute to human development through household and community activity, and at the same time progress in human development is expected to improve women empowerment through improved health, nutrition, education, social security, political freedom, availability of employment and standard of living. Therefore, the level of human development is mainly determined by the level of women empowerment.

\section{Study Area}

The Karnataka state lies in the south-western part of the Indian peninsular. The Karnataka state extends for about $750 \mathrm{Kms}$ from north to south and about $400 \mathrm{Kms}$ from east to west. The total land area is $1.91 .791 \mathrm{sq} \mathrm{kms}$. It accounts for $5.83 \%$ of the total area of the country (32.88 lakhs sq Kms) and ranks $8^{\text {th }}$ among the major states of India in terms of size. As per the 2011 provisional census, the state's population is 6.11 crores, out of which 3.1 crores are males and 3.0 crores are females. 
Karnataka occupies 9 th place (5.05\% of the country total population) in India with regard to population. In 2011, the state had 30 districts, 176 Taluks, 29340 villages, and 347 towns.

Karnataka

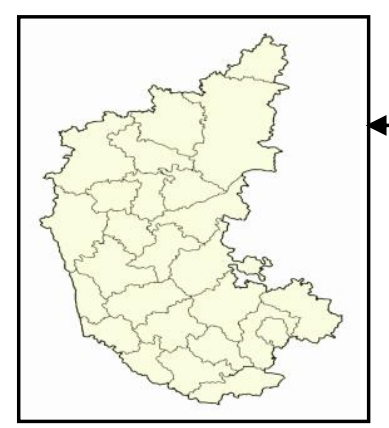

India

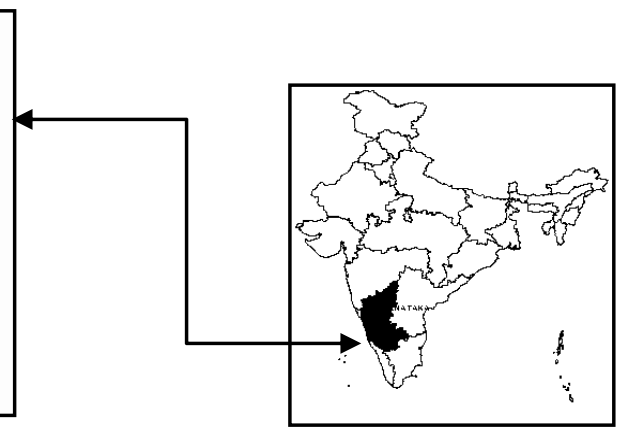

Fig.1. Study area (Karnataka State)

Source: Karnataka HDI report 2005

\section{Women Empowerment: A Brief Review}

Empowerment of women is essential for the sustainable development of India. India's first Prime Minister Pundit Jawaharlal Nehru said that "you can tell the condition of a nation by looking at the status of its women". This statement stresses the important role that women have in our society. Even after 65 years of independence, equality between men and women seems a distant dream, here in India. Everywhere women have to face inequality, discrimination and exploitation from all angles like socio-culturally, economically, politically, demographically and sexually.

A number of studies have already been undertaken both on women empowerment and its relationship with development and also a large number of books have been published covering the theme of women empowerment. Women empowerment is a multidisciplinary concept and it has been defined in many ways. A number of scholars have attempted to conceptualize and measure women's Empowerment since the 1980s. Sen (1981), Schuler and Hashemi (1993), UNDP (1995), Kabeer (2000), Malhotra et.al. (2002) 
and others have contributed towards the conceptualization and Measuring of women's Empowerment in a number of ways.

According to the Karnataka Human Development Report (2005), Empowerment, conceptually, has certain key components: (I) it radically shifted from the old top-down 'welfare' approach of treating women as a disadvantaged group in need of handouts, towards a recognition of the structural roots of gender bias; (ii) it addressed the issue of power and powerlessness that goes with gender and other forms of inequality; (iii) most significant is the recognition that a change in power relations, requires not only a change in control over external resources such as land and income but also a change in the person's sense of self-worth and confidence; (iv) it emphasized the importance of group processes and solidarity as a way of breaking the cycle of hopelessness and helplessness that unequal gender relations perpetuate.

P. Vijayaleksmi Pandit (1997) is of the opinion that, education of women is a critical input for improving nutritional levels, increase the age of marriage, improvement of self-image and their empowerment through gainful employment. Kurukshetra: A Journal on Rural Development (2008), in their January issue mainly focused on empowerment of women and opined that although women were the active agents for sustainable development, and their empowerment was very important for the process of development, they had not actively participated in their own emancipation mainly due to low economic independence. Imran Sharif Chaudhry and Farhana Nosheen (2009), in their article found out that, woman empowerment is considerably influenced by education, access to media, socio-cultural norms of the community, job of women and household participation rate. M. M. Varma (2009) in his article enlightens the various approaches adopted from time to time to empower women in India. Vijaya K. Kulkarni and L. D. Vaikunthe (2009), in their article concluded that employment of women enables her to make and enforce decisions on family matters, through her control over economic resources. This leads to a decrease in the differentiation of gender bias in the family and also increases the empowerment of the working women. K. R. Lakshmy Devi and P. Uma (2010), in their article mentioned that, to empower women along with income and credit facilities, 
measures like skill upgradation, better education, social and political consciousness are very much important to challenge the existing gender inequalities in the society.

Thus, quite a number of studies have already been undertaken on women empowerment and its various dimensions like socioeconomic, psychological, legal, political and familial aspects. In this context, the present paper is an endeavour to analyse the regional disparities in the level of women empowerment, along with the distribution of Human development, and to find out whether there is any relationship between them.

\section{Objectives}

The main objectives of the paper are

1. To analyse the regional pattern of the levels of Women empowerment.

2. To study the spatial pattern of the distribution of Human development in Karnataka.

3. To find out the relationship between the level of women empowerment and Human development Index in Karnataka.

\section{Database and Methodology}

The present study is based on the secondary data. Mainly, the following documents are used to obtain the required data, related to the selected variables;

1. Indian Census report-2001

2. Provisional Population Totals-2011, Karnataka Series 30

3. Karnataka State Human Development Report-2005

4. Other Reports of Government, NGOs and research articles on women Issues and Empowerment

After collecting data, these were compared and analyzed in a suitable manner by using simple statistical tools. At present, the Karnataka state comprises of 30 districts, but information required for the present study is not available for newly formed districts i.e. Ramanagara, Chikkaballapura and Yadgir. Therefore the study has 
been used for the old Classification of 27 Districts of Karnataka according to the 2001 population census.

The study grouped the districts according to (1) level of women empowerment, (High, Medium, Less) and (2) Human Development Index (High, Medium, Less) and studied each group separately with the help of various empowerment indicators like female literacy rate, sex ratio, etc. Grouping of districts on the basis of composite score are presented in Table 2.

Five indicators have been used to construct the composite score of the level of women empowerment. These are, X1 - Total Sex ratio, X2 - Child sex ratio, X3 - Total crime against women, X4 - Female Literacy rate and $\mathrm{X} 5$ - $\%$ of female working population to total working population.

For measuring the level of women empowerment in Karnataka, scholars have used Kendal's ranking method. The ranks of all the variables have been given in ascending order except total crime against women, which has been given in descending order. Similarly, district wise human development index were also arranged in descending order for the demarcation of high, Medium and less human development districts based on Human Development index, and finally the same has been shown on the map using choropleth method.

Further, to find out the relationship between Human Development index and the level of women empowerment in Karnataka, Spearmen's co-relation technique has been used.

\section{Discussion}

The present investigation attempts to show the spatial pattern of distribution of the HDI and the level of women empowerment in the Karnataka state, taking the district as a unit of analysis.

Spatial analysis of indicators of the level of women empowerment

\section{a. Sex ratio}

The balance between the sexes is an important aspect of population structure, because all other population characteristics may be 
influenced by the ratio between the two sexes and it is also an important indicator to identify the gender disparity.

In the study region, all the districts except Dakshina Kannada (1022), Udupi (1130), Hassan (1004) have less than 1000 females per 1000 male population. Northern districts such as Gadag, Bidar, Belguam, Bijapur, Raichur, etc. have very less sex ratio compared to the other regions. The Bangalore urban district has a very low sex ratio (908).

\section{b. Child sex ratio}

The child sex ratio of the country (India) and the state (Karnataka) has been decreasing decade by decade; there is more gender inequality in the child sex ratio. All the districts of the state have child sex ratio of less than 1000 female child population per1000 male child population. Kodagu district has 977 and Belgaum has 924 female children per 1000 male children.

\section{c. Female literacy rate}

Female education is an integral part of the level of women empowerment. The level of education shows the situation of the female in the society. Gandhiji has pointed out that "Educating a woman, it leads to education of generation". According to the 2001 census, the highest literacy rate is confined to southern and coastal Karnataka namely; Bangalore, Udupi, Dakshina Kannada, Uttara kannada, Hassan and Kodagu, contrary to the northern districts such as Bidar, Raichur, Belguam, Bijapur, Bagalkote, Gadag etc. which have less female literacy rate in the state. The remaining districts have a medium literacy ratio.

Bangalore urban district $(77.48 \%$ ) has got the first rank and Raichur has got $(35.93 \%)$ the last rank in the state.

\section{d. Working female population}

The composition of the female working force is the reflection of the economic status of women in the society and the family; economic well-being is very important for women empowerment. Around 30 $-35 \%$ of the female are working in different sectors and around 60 $-65 \%$ of the workers are males in the state. 
Dakshina Kannada (41.7\%) and Tumkur (41.3\%) have first and second ranks regarding the female working population in the state. Mysore (26\%) and Bangalore urban (18\%) have got the $26^{\text {th }}$ and $27^{\text {th }}$ position in the state.

\section{e. Total crime against women}

The Total number of crime against women is also another important indicator to show the condition of women in the society. The number of crime is more in Bangalore urban (1125) and less in Dakshina Kannada (37), mainly because of more urbanization, modernization etc.

Table.1 The level of women empowerment and no. of districts of Karnataka state (2001)

\begin{tabular}{|l|l|c|l|}
\hline Composite Score & \multicolumn{1}{|c|}{ Level } & No. of Districts & \multicolumn{1}{|c|}{ Name of the Districts } \\
\hline$>60$ & $\begin{array}{l}\text { High } \\
\text { Development }\end{array}$ & $8(27 \%)$ & $\begin{array}{l}\text { Udupi, Dakshina kannada, Kodagu, Hassan, } \\
\text { Tumkur, Kolar, Chikkamagalore, Gadag }\end{array}$ \\
\hline $61-80$ & $\begin{array}{l}\text { Medium } \\
\text { Development }\end{array}$ & $9(33 \%)$ & $\begin{array}{l}\text { Chamarajanagara, Mysore, Chitradurga, } \\
\text { Shimogha, Haver, Uttara kannada, } \\
\text { Dharwadh, Koppala, Raichur }\end{array}$ \\
\hline$<81$ & $\begin{array}{l}\text { Less } \\
\text { Development }\end{array}$ & $10(36 \%)$ & $\begin{array}{l}\text { Mandya, Bangalore urban, Bangalore rural, } \\
\text { Davangere, Bellary, Bagalkote, Belgaum, } \\
\text { Bijapur, Gulbarga, Bidar }\end{array}$ \\
\hline Total & - & $27(100)$ & \\
\hline
\end{tabular}

Source: Census of India 2001 and Karnataka state Human Development report 2005

Figures in parenthesis indicate \% to total no. of Districts.

Out of 27 districts, 8 districts have High level of women empowerment. Out of them, Seven districts are mainly located in the southern and coastal part constituting of Dakshina Kannada, Hassan, Kodagu, Kolar, Udupi, Chikkamagalore and Tumkur mainly due to the better sex ratio, literacy rate etc. and the remaining Gadag district located in the northern part of the state has high level of women empowerment, mainly because the district got $6^{\text {th }}$ rank for female working population and the $3^{\text {rd }}$ rank for crime against women.

The moderate women empowerment is observed mainly in the middle part of Karnataka, and few in southern Karnataka (2 districts) viz, Mysore, Chamarajanagara, Uttara Kannada, Raichur, Koppala, Dharwadh, Shimogha, Chitradurga and Haveri, mainly 
because of the medium development in the literacy rate, working population and sex ratio.

Table. 2 Districtwise analysis of the level of women empowerment in Karnataka State (2001)

\begin{tabular}{|c|l|l|l|l|l|l|l|l|l|l|l|l|}
\hline SINo & Districts & F.L.R & R & S.R & R & C.S.R & R & W.F.P & R & T.C.A.W & R & Total \\
\hline & & & & & & & & & & & & Score \\
\hline 1 & Bagalkote & 43.6 & 22 & 980 & 9 & 939 & 23 & 33.3 & 16 & 180 & 14 & 84 \\
\hline 2 & Bangalore & 55 & 14 & 955 & 22 & 940 & 22 & 34.7 & 11 & 289 & 23 & 91.5 \\
\hline 3 & Bangalore & 77.5 & 1 & 908 & 27 & 941 & 21 & 18.7 & 27 & 1125 & 27 & 103 \\
\hline 4 & Belgaum & 52.3 & 17 & 960 & 20 & 924 & 27 & 32.7 & 17 & 346 & 24 & 105 \\
\hline 5 & Bellary & 45.3 & 21 & 969 & 14 & 949 & 17 & 35.9 & 9 & 262 & 20 & 80.5 \\
\hline 6 & Bidar & 48.8 & 20 & 949 & 24 & 967 & 5 & 26.2 & 25 & 196 & 15 & 89 \\
\hline 7 & Bijapur & 43.5 & 23 & 950 & 23 & 971 & 3 & 28.5 & 22 & 222 & 18 & 89 \\
\hline 8 & Chamarajna & 42.5 & 24 & 971 & 13 & 957 & 11 & 31.1 & 18 & 81 & 6 & 71.5 \\
\hline 9 & Chikkamag & 64 & 7 & 984 & 6 & 964 & 6.5 & 30.9 & 19 & 215 & 17 & 55.5 \\
\hline 10 & Chitradurga & 53.8 & 15 & 955 & 22 & 946 & 19 & 37.7 & 7 & 133 & 10 & 72 \\
\hline 11 & Dakshin & 77.2 & 2 & 1022 & 2 & 952 & 14 & 41.7 & 1 & 37 & 1 & 19.5 \\
\hline 12 & Davangere & 58 & 10 & 962 & 19 & 949 & 17 & 30.1 & 20 & 250 & 19 & 84.5 \\
\hline 13 & Dharwad & 61.9 & 8 & 949 & 25 & 944 & 20 & 28.6 & 21 & 38 & 2 & 76 \\
\hline 14 & Gadag & 52.5 & 16 & 969 & 15 & 951 & 15 & 37.8 & 6 & 40 & 3 & 55 \\
\hline 15 & Gulbarga & 37.9 & 26 & 966 & 17 & 937 & 25 & 34.9 & 10 & 408 & 25 & 103 \\
\hline 16 & Hassan & 59 & 9 & 1004 & 3 & 964 & 6.5 & 39.7 & 3 & 269 & 22 & 43.5 \\
\hline 17 & Haveri & 57.4 & 11 & 944 & 26 & 961 & 9 & 33.7 & 15 & 122 & 9 & 70 \\
\hline 18 & Kodagu & 72.3 & 4 & 996 & 4 & 977 & 1 & 36.2 & 8 & 77 & 5 & 22 \\
\hline 19 & Kolar & 52.2 & 18 & 972 & 11 & 976 & 2 & 39 & 4 & 167 & 12 & 47 \\
\hline 20 & Koppal & 39.6 & 25 & 983 & 7.5 & 938 & 24 & 38.9 & 5 & 95 & 8 & 69.5 \\
\hline 21 & Mandya & 51.5 & 19 & 986 & 5 & 937 & 26 & 33.9 & 13 & 421 & 26 & 89 \\
\hline 22 & Mysore & 55.8 & 13 & 964 & 18 & 970 & 4 & 25.3 & 26 & 214 & 16 & 77 \\
\hline 23 & Raichur & 35.9 & 27 & 983 & 7.5 & 962 & 8 & 34.6 & 12 & 162 & 11 & 65.5 \\
\hline 24 & Shimogha & 66.9 & 6 & 978 & 10 & 959 & 10 & 28 & 23 & 264 & 21 & 70 \\
\hline 25 & Tumkur & 56.9 & 12 & 967 & 16 & 952 & 14 & 41.3 & 2 & 172 & 13 & 56.5 \\
\hline 26 & Udupi & 75.2 & 3 & 1130 & 1 & 955 & 12 & 33.9 & 14 & 48 & 4 & 34 \\
\hline 27 & Uttara & 68.5 & 5 & 971 & 13 & 946 & 19 & 27.8 & 24 & 83 & 7 & 67 \\
\hline & & & & & & & & & \\
\hline
\end{tabular}

Source: Census of India 2001 and Karnataka state Human Development report 2005

F.L.R - female Literacy rate, S.R - Sex ratio, C.S.R - Child sex ratio, W.F.P - working female Population, T.C.A.W - Total crime against women, $\mathrm{R}-$ Rank

The lowest level of women empowerment is noticed in the rest of the districts (10 districts), but many more of them are concentrated in the northern parts (7 districts) of the state namely; Bellary, Bagalkote, Bijapura, Gulbarga, Bidar, Davangere and Belgaum (Table.1 and map.2) and three other districts such as Mandya, Bangalore urban and rural districts have low level of women empowerment due to less sex ratio, child sex ratio and more crime against women. 


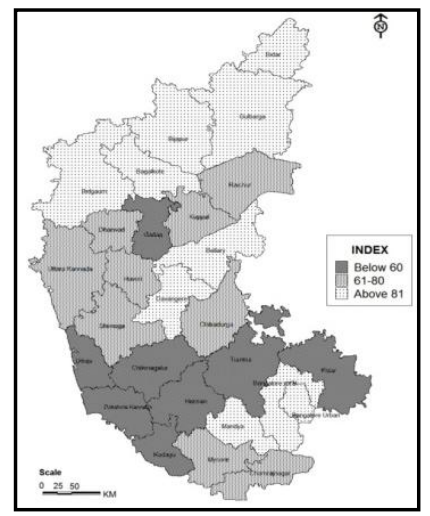

Fig. 2 Spatial pattern of the level of women empowerment in Karnataka state (2001)

Source: Karnataka HDI report 2005

\section{Spatial Pattern of the Distribution of HDI}

The Human Development Index (HDI) computed every year since 1990 by the UNDP, measures average achievements in basic human development and assigns ranking to countries. It shows the level of development, especially the socio-economic and health condition or situation of the region. The level of women empowerment is a reflection of Human development and it is an output of socio economic development. High human development leads to high level of women empowerment. In this context, the present investigation attempts to show the spatial pattern of Human development in the districts of the state.

To show the spatial pattern of the distribution of Human development, the Human Development Index was used and twenty seven districts have been divided into three categories based on ranks, which the districts have got for HDI. The areas of high human development stretches over 9 districts (starting 9 districts), 8 of these districts are located in the southern part of the state, viz., Kodagu, Bangalore, Bangalore urban, Chikkamagalur, Dakshin kannada, Shimogha and Udupi and one district namely Belgaum is located in Northern Karnataka. The medium level has been found in 9 districts, ranking from $10^{\text {th }}$ to the $18^{\text {th }}$. Seven districts out of these are mainly concentrated in the middle of Karnataka and South Karnataka (Tumkur, Bellary, Chitradurga, Davangere, Hassan, Kolar, and Mysore). The remaining two 
districts found in north Karnataka are namely, Gadag and Dharwadh. Out of the 9 districts, (ranking from 19th to 27th) Mandya and Chamarajanagara districts from south Karnataka have less human development, the remaining 7 districts are found in North Karnataka.

Table.3 District wise distribution of Human development index and ranks

\begin{tabular}{|l|l|l|}
\hline Districts & HDI & Rank \\
\hline Bagalkote & 0.591 & 22 \\
\hline Bangalore rural & 0.653 & 6.5 \\
\hline Bangalore & 0.753 & 1 \\
\hline Belgaum & 0.648 & 8 \\
\hline Bellary & 0.617 & 18 \\
\hline Bidar & 0.599 & 21 \\
\hline Bijapur & 0.589 & 23 \\
\hline Chamarajnagara & 0.576 & 25 \\
\hline Chikkamagalur & 0.647 & 9 \\
\hline Chitradurga & 0.627 & 16 \\
\hline Dakshin kannada & 0.722 & 2 \\
\hline Davangere & 0.635 & 13 \\
\hline Dharwad & 0.642 & 10 \\
\hline Gadag & 0.634 & 14 \\
\hline Gulbarga & 0.564 & 26 \\
\hline Hassan & 0.639 & 11 \\
\hline Haveri & 0.603 & 20 \\
\hline Kodagu & 0.697 & 4 \\
\hline Kolar & 0.625 & 17 \\
\hline Koppal & 0.582 & 24 \\
\hline Mandya & 0.609 & 19 \\
\hline Mysore & 0.639 & 12 \\
\hline Raichur & 0.547 & 27 \\
\hline Shimogha & 0.673 & 5 \\
\hline Tumkur & 0.63 & 15 \\
\hline Udupi & 0.714 & 3 \\
\hline Uttara kannada & 0.653 & 6.5 \\
\hline & & \\
\hline & & \\
\hline
\end{tabular}

Source: Karnataka HDI report 2005 


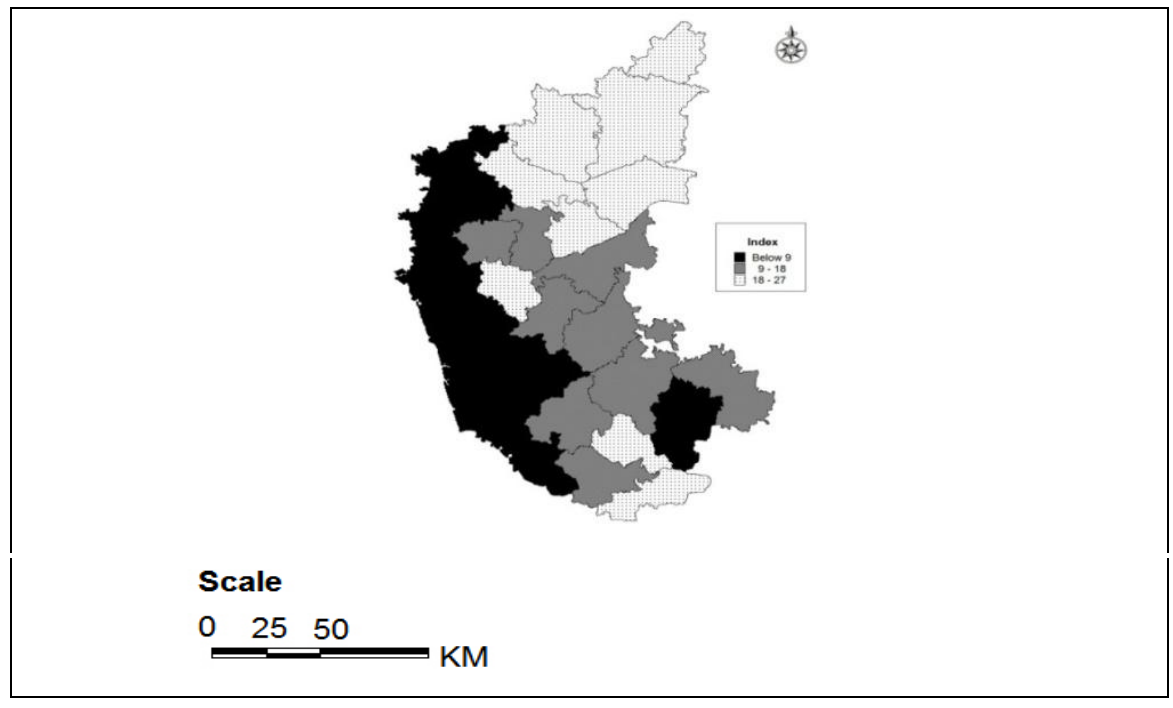

Fig.3 District wise distribution of Human development index and ranks

Source: Karnataka HDI report 2005

Thus, the analysis indicates that HDI and the level of women empowerment are both correlated with each other. Both high human development and the level of women empowerment are located in mainly the southern and coastal parts of the state, contrary to the low level of these two factors that are found mainly in the northern parts of the state.

\section{Relationship between HDI and the level of women empowerment}

In this part, the paper has attempted to find out the relationship between Human Development Index and the level of women empowerment with the help of the correlation technique.

Table 4 Relationship between HDI and the level of women empowerment

\begin{tabular}{|l|l|}
\hline $\begin{array}{l}\text { Indicators of women } \\
\text { empowerment }\end{array}$ & $\begin{array}{l}\text { Relationship with } \\
\text { HDI }\end{array}$ \\
\hline Sex ratio & 0.3 \\
\hline Child sex ratio & 0.28 \\
\hline Female literacy rate & 0.87 \\
\hline Female working population & 0.7 \\
\hline Total crime against women & 0.29 \\
\hline
\end{tabular}

Source: Karnataka HDI report 2005 
The table.4 clearly shows that, there is a positive relationship between the level of women empowerment and HDI in the state. In case of the female working rate and female literacy rate, they have a high positive correlation than the other indicators.

However, finally the study reveals that the level of HDI, leads to the level of the status of the women in the state.

\section{Conclusion}

The paper presents the spatial pattern of distribution of the HDI and the level of women empowerment in Karnataka, taking the district as a unit of analysis. This analysis is carried out with a limited number of indicators, but can be extended to a larger number of indicators. It was observed that the 5 indicators for the purpose of this analysis were found to have a positive relationship with HDI in the state. The female working rate and female literacy rate, have high positive correlation than the other indicators of women empowerment. Southern and coastal districts of Karnataka have high human development index as well as high level of women empowerment. On the other hand, the northern districts of Karnataka are found to be backward in terms of overall empowerment of women along with the HDI. The condition of women status and human development index are at a very poor level in the northern districts.

It can be concluded that, in the southern and coastal districts of Karnataka, there is a need to improve the condition of women status and other socio-economic development indicators, while in the northern districts of Karnataka, there is a need to give greater attention for the improvement of the level of women empowerment and human development. Therefore, the policy makers should focus their efforts particularly on the districts that have performed poorly in the women empowerment and human development status.

\section{Recommendations}

The present study throws light on the level of women empowerment and also its relationship with the human development index in the Karnataka state. Results found that in 
spite of implementing a number of programmes and policies by the government and also efforts from the non-governmental organizations, women are disempowered absolutely and relatively when compared to men. The major recommendations of the study are,

- Literacy plays an important role in empowering women. In the study, it was found that the regions of Bidar, Raichur, Belguam, Bijapur, Bagalkote and Gadag districts are poor performers as far as the literacy rate is concerned. The Government of Karnataka should take necessary action to enhance the literacy level of women in those districts.

- To conduct awareness programmes on women's health and nutrition, education, gender awareness, legal and political rights etc., especially in the rural areas.

- To take up specific programmes and policies to improve the level of the status of women in those areas, where the level of women empowerment and HDI are relatively low.

- To set up proper monitoring and implementing authorities to implement various programmes and polices passed by the central and state government.

- To strengthen the Non-Governmental organizations and public sectors, those that are providing extensive services to women and working for the empowerment of women in the rural as well as the urban areas.

- NGOs, civil society forums and social service activists can play an active role in identifying and alerting authorities on crime against women.

- Enlightened individual women should organize awareness camps at the grass root level, to make their sisters aware of themselves

- Civil society should encourage women's active participation in the political system.

\section{References}

Chaudhry, I. S., \& Nosheen, F. (2009). The determinants of women empowerment in Southern Punjab (Pakistan): An empirical analysis. European Journal of Social Sciences, 10(2), 216-229. 
Kabeer, N. (2000). Reflections on the measurement of empowerment: Theory and practice in discussing women's empowerment. Sida Studies, 3.

Government of India, (2001). Census report.

Government of Karnataka, Planning and statistics department of Karnataka. (2005). Karnataka human development report.

Kulkarni, V. K., \& KuVaikunthelkarni, L. D. (2009). Employment and empowerment of women. Journal of Development and Social Change, 6, 3-4.

Devi, K. R. L. \& Uma, P. (2010). Development programmes and women's empowerment-Kerala experience. Journal of Rural Development, 39(3), 295-305.

Malhotra, A., Schuler, S. R., \& Boender, C. (2002). Measuring women's empowerment as a variable in international development.

Meera, B. (2006). Women and economic reforms, Kerala experience. New Delhi: Serials Publications.

Pandit, P.V. (1997). Empowerment of women through distance education. New Delhi: Book Links Corporation.

Government of Karnataka, Directorate of Census Operations. (2011). Provisional population totals- 2011. (Karnataka Series 30)

Schuler, S. R., \& Hashemi, S. M. (1993). Defining and studying empowerment of women: A research note from Bangladesh. In S. R. Schuler (Ed.), JSI Working Paper No.3. VA: Arlington.

Sen, A. K., (1981). Poverty and famines: An essay on entitlement and deprivation. Oxford: Oxford University Press

UNDP. (1995). Human development report 1995. Oxford: Oxford University Press.

Varma, M. M. (2009). Approaches to women's empowerment: An overview. IASSI Quarterly (Special Issue), 28(Jan-Dec 2009), 230-249. 